\title{
Public Awareness of Nature and the Environment During the COVID-19 Crisis
}

\author{
Sandra Rousseau ${ }^{1}$ (D) Nick Deschacht ${ }^{2}$
}

Accepted: 3 July 2020 / Published online: 12 July 2020

(c) Springer Nature B.V. 2020

\begin{abstract}
As our behavioral patterns change due to the COVID-19 crisis, our impact on nature and the environment changes too. Pollution levels are showing significant reductions. People are more aware of the importance of access to local green and blue spaces. By analyzing online search behavior in twenty European countries, we investigate how public awareness of nature and the environment has evolved during the COVID-19 crisis. We find that the crisis goes hand in hand with a positive shift in public awareness of nature-related topics, but that awareness of environmental topics remains unaffected. While the decreasing pollution levels and media attention may reduce the overall sense of urgency to tackle pollution problems, the increased experience with local natural resources may strengthen public support for a recovery program that puts the transition towards a more sustainable economic system centrally.
\end{abstract}

Keywords Public awareness · Google Trends · COVID-19 · Nature · Environment

\section{Introduction}

The COVID-19 crisis has a massive impact on the world and our behavior. International transport flows have plummeted but also within-country traffic flows have significantly reduced as we are all strongly encouraged, or even mandated, to stay and work at home. As our behavioral patterns change, our impact on nature and the environment changes as well. People are more and more aware of the importance of access to local green and blue spaces and personal experiences with the local natural environment are rapidly increasing during daily walks and runs. Gardens have become a highly appreciated asset. Urban nature plays a critical role in local resilience during this crisis by maintaining physical and mental well-being (Samuelsson et al. 2020). Urban nature can provide people with opportunities to escape household confinement and enjoy positive well-being effects (Bertram

Sandra Rousseau

sandra.rousseau@kuleuven.be

1 CEDON, Faculty of Economics and Business, KU Leuven, Warmoesberg 26, 1000 Brussels, Belgium

2 ECON, Faculty of Economics and Business, KU Leuven, Warmoesberg 26, 1000 Brussels, Belgium 
and Rehdanz 2015), maintain social contacts (Jennings and Bamkole 2019) and provide a sense of connection with the outside world (Whitburn et al. 2019). Familiarity and experience with nature can influence people's valuation and appreciation of natural resources (LaRiviere et al. 2014). Even brief contact with the natural environment can boost feelings of connectedness with nature and mood (Nisbet et al. 2019). The frequency of visits is a strong predictor for a higher disposition to protect ecosystems and biodiversity (Tyrväinen and Väänänen 1998; Kwak et al. 2003; Lo and Jim 2010). Overall, when people feel connected with nature, they are more inclined to spend time in it (Lin et al. 2014) and protect it (Schultz 2002). Thus, we expect that public awareness of nature may be increasing during the COVID-19 crisis.

Besides the impact on nature experiences, the forced shift in behavioral patterns resulted in significant reductions in pollution levels (Helm 2020). Daily global $\mathrm{CO}_{2}$ emissions fell by $17 \%$ by early April 2020 compared with the mean 2019 levels, mostly due to changes in surface transport (Le Guéré et al. 2020). In its Global Energy Review 2020, the International Energy Agency has predicted an 8\% drop in global $\mathrm{CO}_{2}$ emissions, to reach a decline of $30.6 \mathrm{Gt}$ for 2020 compared to 2019 (IEA 2020). Such a reduction would be the largest ever, six times larger than the previous record reduction of .4 Gt in 2009 due to the financial crisis. Also, local air pollution levels are positively affected: nitrogen dioxide pollution over northern China, western Europe and the U.S. decreased by as much as 60 percent in early 2020 compared to the same period last year (Bauwens et al. 2020). Water quality is showing signs of improvement as well. A decrease in suspended particulate matter concentrations by $15.9 \%$ was found in Vembanad Lake, India, compared with the prelockdown period (Yunus et al. 2020). Still, the emission reductions in transportation and industry did not help to avoid severe air pollution in China (Wang et al. 2020). As COVID19 has dominated the news and social media for the past months, communication about these and other pollution problems has substantially reduced. Yet, when pollution trends were reported in media and scientific reporting during the COVID-19 crisis, the message has been positively framed in general by pointing out (short-term) reductions in emissions. Thus, we expect that the public perception of the urgency of environmental problems may be decreasing and that the public awareness of environmental issues, in general, may be largely unaffected by the COVID-19 crisis.

Insights into public awareness levels, which we measure by online search behavior, are important inputs for the long-term recovery strategies after the COVID-19 crisis as public opinion - supportive or otherwise - is a key determinant of policy change in democratic countries (e.g., Burstein 2003; Dalton 2013; Millner and Ollivier 2016). For example, as public opinion shifts towards prioritizing the environment, there is a significant and positive effect on the rate of renewable energy policy outputs by governments in Europe (Anderson et al. 2017). As another example, Herrnstadt and Muehlegger (2014) show that the effects of abnormal weather extended beyond increased online search behavior for 'climate change and 'global warming' to observable action on environmental issues measured by voting records of the US Congress. Public support is determined by perceptions, emotions, physical characteristics of the pollution, economic circumstances and geography, but also by the amount of media coverage (Drews and van den Bergh 2016). The impact of media coverage can have a positive, but also a negative, impact on public support for environmental policies depending on the content and framing of the message, the source of the information and individual characteristics (Bostrom et al. 2012).

We investigate how public awareness of nature and the environment, measured by online search behavior in twenty European countries, is affected by the COVID-19 crisis. The shortterm improvements in several pollution indicators may reduce the sense of urgency to act now 
and the calls for system-wide fundamental actions may be-temporarily-less audible. Several experts and institutions are concerned about this effect. As Inger Andersen, the head of the UN Environment Program (UNEP), said "COVID-19 is not a silver lining for the climate" and "Visible, positive impacts are but temporary, because they come on the back of tragic economic slowdown and human distress" (UN 2020). Furthermore, many environmental experts, politicians and organizations see the recovery from COVID-19 as an opportunity and call for a sustainable, low-carbon recovery strategy of the economy and our society. The European Commission (2020), for example, stated: "Now is the time for our European Union to get back to its feet and move forward together to repair damage from the crisis and prepare a better future for the next generation". A recent editorial in Nature (2020) mentions: "But as economies are revived, now is the right time to make up for past omissions — and rebuild them in a way that takes nature's true value into account". While the decreasing pollution levels may counteract the urgency and validity of these messages, the increased experience and appreciation for local natural resources may provide an opportunity as it may strengthen public support for a recovery program that sees the economy as being embedded in the natural environment.

\section{Methods}

\subsection{Data Collection with Google Trends}

In Europe, Google is the most used search engine online with a market share of more than 90\% in the period from January 2019 till April 2020 (Statcounter 2020). Thus, we use online search behavior recorded on the Google Trends website (trends.google.com) to measure public awareness of nature and the environment. Google Trends has already been used for many purposes such as studying the occurrence of influenza-like diseases (Carneiro and Mylonakis 2009), interest in the environment and biodiversity (Mccallum and Bury 2013; Nghiem et al. 2016), or predicting tourism flows (Siliverstovs and Wochner 2018). Several studies have also used Google Trends to study communication strategies (Husnayain et al. 2020) and public awareness (Hu et al. 2020) during the COVID-19 crisis.

Google Trends can be searched based on 'search terms' or 'topics'. Search terms can be anything and are user-defined, while topics are defined by Google and group all search terms related to this topic. Hence, topics are collections of search terms. Using topics rather than search terms to collect data has several advantages since the relevance of users' searchers for the topic has been checked. Moreover, using a topic search also avoids the problem of incorrectly spelled and incomplete search terms as Google corrects for the most common mistakes. Also, topics are language-neutral, while search terms are not.

Google Trends (GT) measures search popularity in relative terms based on a randomly drawn sample of all search terms used in queries within the chosen period. Let I be the set of search terms (or topics) in which a researcher is interested (e.g. birds), t a time unit within the time horizon $\mathrm{T}$ (e.g. each week in 2020), z the chosen region (e.g. France) and c the chosen category (e.g. animals), then the search popularity indicator of search term i element of set I, is defined as (Siliverstovs and Wochner 2018; Genoe and Rousseau 2020):

$$
S P I_{i, t, c}^{z}=\frac{\theta_{t, z, c}^{i}}{\max _{t \in T, i \in I}\left\{\theta_{t, z, c}^{i}\right\}} \times 100
$$

with 


$$
\theta_{t, z, c}^{i}=\frac{\# \text { searches for term } i \text { in category } c, \text { during time unit } t \text { in region } z}{\# \text { searches in category } c, \text { during time unit } t \text { in region } z}
$$

Moreover, if the number of searches in the numerator of Eq. (2) is smaller than an (unspecified) threshold, it is set to zero. Google first calculates the relative search volume for each search term $i$ of the set $I$, in each unit period during a predetermined time horizon $\mathrm{T}$, for region $\mathrm{z}$. This relative search volume is then rescaled for the maximum relative search volume for all search terms in the set I. This maximum is set equal to 100 , and all other relative search volumes are expressed as a proportion of this maximum and thus range from 0 till 100.

To capture public awareness of nature and the environment, we selected twelve topics. Six topics are related to nature: forest, birds, nature, biodiversity, gardening and vegetable plot. Six other topics capture environmental issues: climate change, $\mathrm{CO}_{2}$-tax, air pollution, water pollution, noise pollution and circular economy. We observe weekly search behavior from January 1, 2019, till May 11, 2020 for the twenty largest European member states according to population size: Germany, France, Italy, Spain, Poland, Romania, Netherlands, Belgium, Greece, Czech Republic, Portugal, Sweden, Hungary, Austria, Bulgaria, Denmark, Finland, Slovakia, Ireland, and Croatia. The reference point of SPI = 100 was obtained in the week of 3 to 9 May, 2020 for the topic 'birds' in France. All other data points are rescaled accordingly.

As the timing of COVID-19 measures and policy actions differs between the different countries, we first investigate the trend in daily searches for the topic 'coronavirus' between January 1, 2020, and May 11, 2020 to determine the peak for the twenty European countries under investigation (see Fig. 1). While we observe the first peak around the time of the lockdown in Wuhan, China (January 23, 2020), the major peak occurs around March 14, 2020 when confinement measures were put in place in many European countries starting with Italy on March 9, 2020. The timing of this peak, around March 14, is the same when using SPI data based on the topic "corona" or the search term"corona or covid".

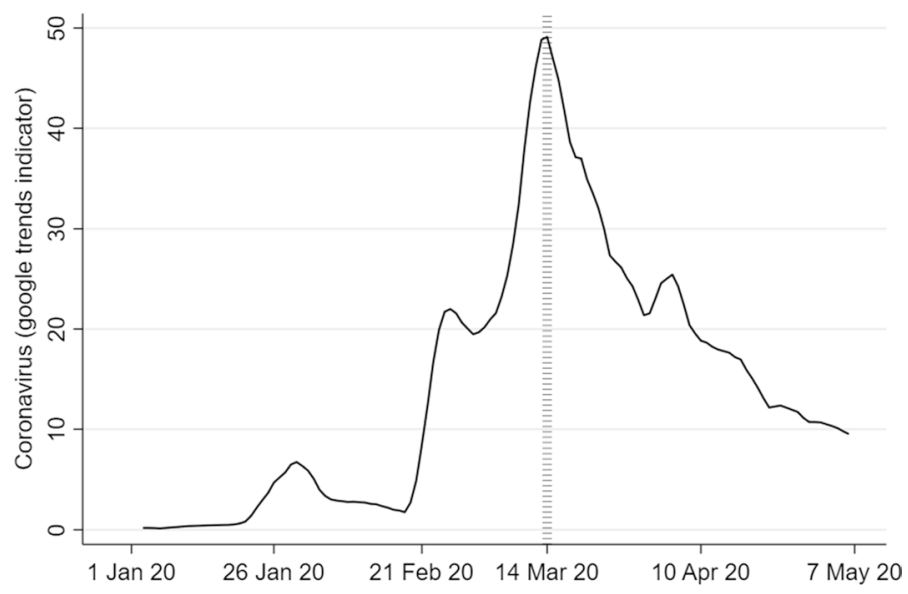

Fig. 1 GT search popularity indicator for daily searches of 'coronavirus'. Notes: Five-day moving average of the Google Trends indicator. Cross-country mean, weighted by population 


\subsection{Difference-in-Difference Approach}

To identify the effect of the COVID-19 crisis on natural and environmental awareness, we compare the difference of the GT search popularity indicator (SPI) for the twelve selected topics before and after the COVID-19 crisis in 2020 with the difference of the indicator over the same period in the year 2019. This "difference-in-differences" approach (DiD) is wellestablished in the literature on impact evaluation and the estimation of treatment effects for its capacity to remove common sources of bias in standard approaches (Angrist and Pischke 2014; Gertler et al. 2016). The DiD approach provides an unbiased estimate of the treatment effect if the change of the outcome variable in the treated group would have been the same as the change in the control group in the absence of treatment (the parallel trends assumption). In the context of the present study, the identifying assumption is that, in the absence of a COVID-19 outbreak, the difference in SPI between the periods before and after March 14th, 2020 would have been the same as the difference between the same periods in 2019 .

In the main analysis, the effect of the COVID-19 crisis on natural and environmental awareness is obtained by estimating the linear regression equation:

$$
S P I_{i j t}=\beta_{0}+\beta_{1} \cdot T_{i j t}+\beta_{2} \cdot D_{i j t}+\beta_{D i D} \cdot T_{i j t} \times D_{i j t}+\alpha_{i}+\gamma_{j}+\varepsilon_{i j t}
$$

where $\beta_{D i D}$ is the DiD estimate of the effect of interest, $S P I_{i j t}$ is the GT search popularity indicator of topic $i$ in country $j$ in week $t, T$ is a time dummy variable distinguishing the period after March 14th $(T=1)$ from the period before $(T=0), D$ is a dummy variable indicating the treatment year and distinguishing the year 2020 in which the COVID-19 crisis occurred $(D=1)$ from the year $2019(D=0), \alpha_{i}$ denote a set of controls for topic fixed effects and $\gamma_{j}$ a set of controls for country fixed effects. The topic and country fixed effects are included in the model because the SPI level depends on the search topic and it varies across countries. In short, the effect of interest $\beta_{D i D}$ captures the increase in the SPI after the COVID-19 crisis within (or "holding constant the average trend in") specific topics and countries, and after netting out seasonality effects in the data.

The periods after and before March 14th used in the analysis are selected in the following way. Let $w$ denote the number of the week within the calendar year so that $w=1$ for the first week of January, $w=2$ for the second week of January, etcetera. The first week after March 14 th is then in week number $w=11$. In our analyses, the period after March 14th is defined as the period of 5 weeks with numbers $14 \leq w \leq 18$. The period before March 14th is defined as the period of 5 weeks with numbers $3 \leq w \leq 7$. In other words, we use a bandwidth of 3 weeks before and after March 14th that is excluded from the analysis to compare periods that are sufficiently separated in time. Thus, our main regression analyses are based on 2400 observations - i.e. 10 weeks of data in 2020, the same weeks of data in the control year 2019 (so 20 weeks in total) for 20 countries and 6 topics related to both natural and environmental awareness. As a robustness check we also perform the analysis based on a bandwidth of 2 weeks, leading to 2880 observations ( 2 times 12 weeks for 20 countries and 6 topics).

\section{Results}

While search behavior for several topics related to nature and environment fluctuates somewhat over time, there has been a clear and rapid increase in the search for naturerelated topics during the COVID-19 crisis after March 14th, 2020 (Fig. 2). The average Search Popularity Index (SPI) for nature-related topics quickly increased by 6 points 


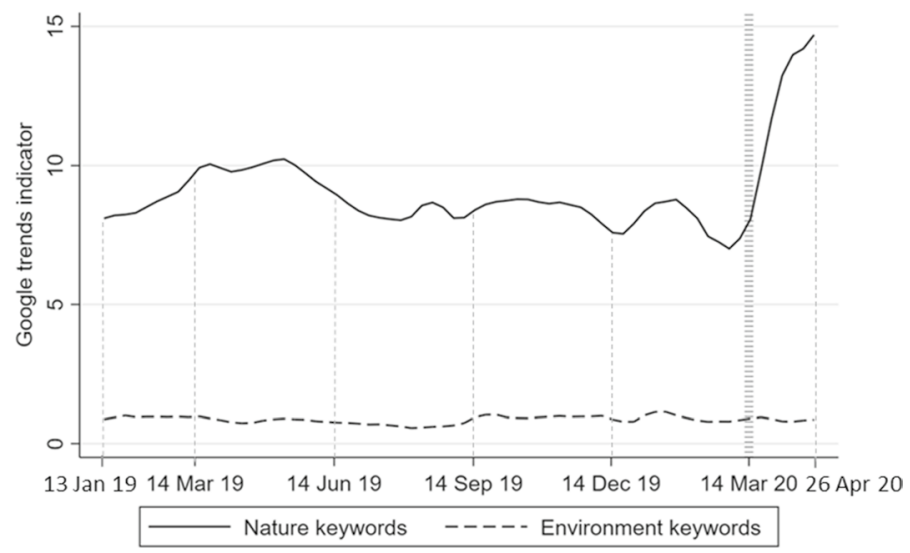

Fig. 2 Search behavior for topics related to nature and environment (January 1st, 2019-May 11th, 2020). Data source: Google Trends. Notes: Three-week moving average of the Google Trends indicator. Mean across keywords (unweighted) and countries (weighted by population size)

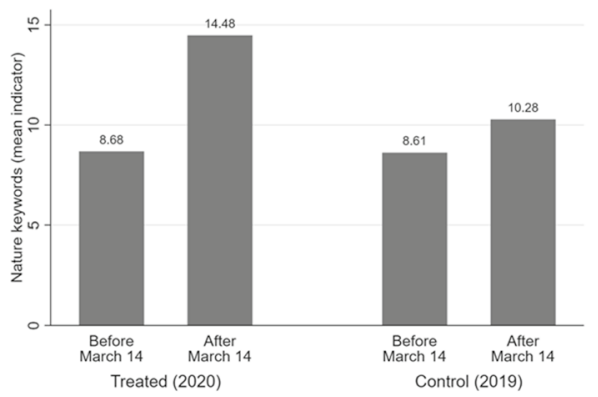

(a) Nature-related topics

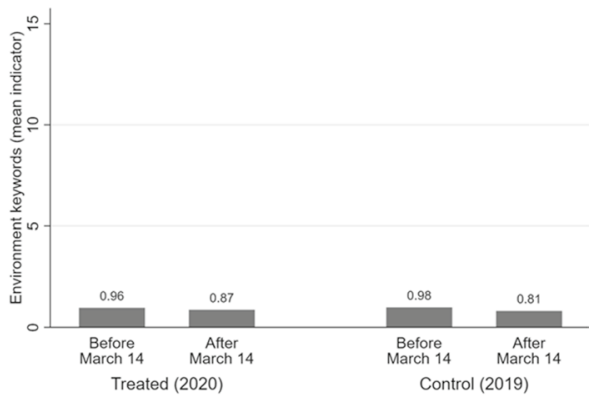

(b) Environment-related topics

Fig. 3 The effect of the COVID-19 crisis on search behavior. Notes: Mean Google Trends indicator across keywords (unweighted) and countries (weighted by population size)

to almost 15 over a short period of time, whereas it had mostly varied between 8 and 10 points before the COVID-19 crisis. The SPI for environment-related topics shows no similar increase after the COVID-19 crisis. The rise in the search for nature-related topics during the spring season in 2019 suggests that seasonality effects should be accounted for to isolate the effects of the COVID-19 crisis.

Using a difference-in-difference approach with a 3 week bandwidth, we compare the increase in the online searches for six nature-related and six environmental topics between the periods before and after March 14th in 2020, with the increase over the same period in 2019 to control for possible seasonal effects (Fig. 3 and Table 1). The effect of the COVID-19 crisis on the search popularity indicator for naturerelated search topics (model 1 in Table 1) was estimated as an increase of 4.138 points $(p<.001)$. The seasonality effect in the case of nature-related topics is estimated to be 1.665 points $(p<.001)$. For the environment-related search topics (model 2 in Table 1$)$, the effects are small and not statistically significant. 
Table 1 The effect of COVID-19 on natural and environmental awareness (regression analysis)

\begin{tabular}{lll}
\hline & $(1)$ & $(2)$ \\
& Nature keywords & Environment keywords \\
& Coef./(SE) & Coef./(SE) \\
\hline Time: after March 14 (T) & $1.665^{* * *}$ & -.174 \\
& $(.272)$ & $(.104)$ \\
Treated: year 2020 (D) & .066 & -.019 \\
& $(.177)$ & $(.076)$ \\
DiD effect (DxT) & $4.138^{* * *}$ & .081 \\
& $(.563)$ & $(.077)$ \\
Country (20 categories) & Yes & Yes \\
Topic (6 categories) & Yes & Yes \\
Observations & 2400 & 2400 \\
\hline
\end{tabular}

$* p<.05 ; * * p<.01 ; * * * p<.001$. The dependent variable is the Google Trends SPI. Linear regression with standard errors clustered at the country-level. Constant terms are included in each model

The results are robust to a change in bandwidth. Based on a bandwidth of two rather than three weeks (see Table 2), the estimated effect of the COVID-19 crisis on the indicator for nature-related search topics becomes an increase of 4.076 points $(p<.001)$ and the seasonality effect is estimated to be 1.575 points $(p<.001)$. For the environment-related search topics the effects are again small and not statistically significant.

The results at the individual topic level (see Table 3) reveal some heterogeneity in the effect of the COVID-19 crisis on the relative online popularity of the twelve topics. A positive effect of the COVID-19 crisis on the SPI is found for all six nature-related topics $(p<.05$ for four out of six topics). The largest positive effects are found for the topics 'birds' (7.800 pts, $p<.001)$, 'forest' $(6.154 \mathrm{pts}, p<.01)$ and 'nature' $(5.175 \mathrm{pts}, p<.001)$. As expected, no significant effect of the COVID-19 crisis on any of the six environmentrelated topics such as climate change or air pollution was found.

Table 2 The effect of COVID19 on nature and environmental awareness (regression analysis with a bandwidth of 2 weeks)

\begin{tabular}{lll}
\hline & $(1)$ & $(2)$ \\
& Nature keywords & Environment keywords \\
& Coef./(SE) & Coef./(SE) \\
\hline Time: after March 14 (T) & $1.575^{* * *}$ & -.148 \\
& $(.264)$ & $(.098)$ \\
Treated: year 2020 (D) & -.212 & -.031 \\
& $(.191)$ & $(.076)$ \\
DiD effect (DxT) & $4.076^{* * *}$ & .102 \\
& $(.562)$ & $(.086)$ \\
Country (20 categories) & Yes & Yes \\
Topic (6 categories) & Yes & Yes \\
Observations & 2880 & 2880 \\
\hline
\end{tabular}

$* p<.05 ; * * p<.01 ; * * * p<.001$. The dependent variable is the Google Trends SPI. Linear regression with standard errors clustered at the country-level. Constant terms are included in each model 
Table 3 Estimated effects by topic

\begin{tabular}{llll}
\hline & $\begin{array}{l}\text { DiD effect: Estim. } \\
\text { coefficient }\end{array}$ & $\mathrm{SE}$ & $\mathrm{N}$ \\
\hline Nature topics & & & \\
Biodiversity & .072 & $(.104)$ & 400 \\
Birds & $7.800^{* * *}$ & $(1.325)$ & 400 \\
Forest & $6.154^{* *}$ & $(1.656)$ & 400 \\
Gardening & $3.682^{*}$ & $(1.613)$ & 400 \\
Vegetable garden & $5.175^{* * *}$ & $(.808)$ & 400 \\
Nature & 1.945 & $(.933)$ & 400 \\
Environment topics & & & \\
CO 2 tax & -.071 & $(.080)$ & 400 \\
Air pollution & .695 & $(.364)$ & 400 \\
Circular economy & -.076 & $(.111)$ & 400 \\
Climate change & -.174 & $(.189)$ & 400 \\
Noise pollution & .145 & $(.072)$ & 400 \\
Water pollution & -.030 & $(.079)$ & 400 \\
\hline
\end{tabular}

$* p<.05 ; * * p<.01 ; * * * p<.001$. Each row presents the estimated coefficient of the DiD term (DxT) in a linear regression model with the SPI for the topic in this row as the dependent variable. Each model includes a constant term, treatment and time indicator variables and country fixed effects. Standard errors clustered at the country-level

\section{Discussion and Conclusion}

The true extent of the global impact of the COVID-19 crisis has yet to be fully determined, but that it will be immense is uncontested (Helm 2020). Initially, short-term rescue actions will be needed to help those who were affected most. However, long-term recovery will require substantial investments in physical, human and natural capital. Thus, the COVID-19 crisis provides us with the opportunity to not just restart, but to redesign, investments and to initiate a transformation to a new form of growth, focusing on resilience, well-being and sustainability (Bhattacharya and Stern 2020). This societal change will need to rely on cross-fertilization between economic and social recovery programs, environmental policies such as climate actions and biodiversity conservation programs such as the recently adopted EU Biodiversity Strategy for 2030.

Public support for green and sustainable recovery policies will play an important role and cannot be taken for granted. Communication strategies and framing of the recovery actions after the COVID-19 crisis will be important. Our analysis of online search behavior in the European Union indicates that the behavioral changes associated with the crisis are accompanied by positive changes in public awareness regarding (local) natural resources such as forests and birdlife. Increased experience with and appreciation of green spaces and wildlife can-partly-underpin this growth in awareness. However, public awareness of environmental issues such as climate change was found to be unaffected by the COVID-19 crisis based on online search trends. The general increasing sense of urgency for many environmental problems may have been counteracted by the reduction in media attention and the short-term positive trends reported for several pollution levels. 
Our findings suggest that public support for programs aiming at more resilient and sustainable living environments may have increased. Communication about climate adaptation strategies may benefit from stressing the pivotal role of urban green and blue spaces especially if these spaces would also be publicly accessible. Framing the decarbonization of transport systems as a means to support walking and cycling as well as to protect green spaces rather than directly promote them as climate policy measures may increase public support. Co-benefits of environmental policies, especially those related to nature and biodiversity conservation, may thus play an even more important role in the future after COVID-19.

While we find evidence of changes in public awareness, these changes may be shortlived and people may revert to previous patterns once the crisis is past. People's habits and behaviors are influenced by many factors such as available time and income. As societies recover from the crisis, behavioral changes may again be reversed as choice determinants and context change. Thus, in order to benefit from the increased support for nature and biodiversity, it may be important to act quickly and to incentivize a long-term change by, for example, supporting urban schemes for greening built infrastructure and creating livable cities.

Finally, the COVID-19 crisis has also shown individuals that individual action, especially on a global scale, can make a difference and can create general common benefits that are noticeable on a large scale. Together we were able to flatten the curve. This real-life experience can act as a trigger to use individual behavioral changes to tackle public-good problems such as climate change and biodiversity conservation.

Acknowledgements We would like to thank Ronald Rousseau for his comments on a previous version of the study.

Data Availability The datasets generated during and/or analyzed during the current study are available from the corresponding author on request.

\section{References}

Anderson B, Böhmelt T, Ward H (2017) Public opinion and environmental policy output: a cross-national analysis of energy policies in Europe. Environ Res Lett 12(11):114011

Angrist J, Pischke J-S (2014) Mastering metrics: the path from cause to effect. Princeton University Press, Princeton

Bauwens M, Compernolle S, Stavrakou T, Müller JF, Van Gent J, Eskes H, Levelt PF, Van der AR, Veefkind JP, Vlietinck J, Yu H (2020) Impact of coronavirus outbreak on NO2 pollution assessed using T ROPOMI and OMI observations. Geophys Res Lett. https://doi.org/10.1029/2020g1087978-\&gt

Bertram C, Rehdanz K (2015) The role of urban green space for human well-being. Ecol Econ 120:139-152

Bhattacharya A, Stern N (2020) From rescue to recovery, to transformation and growth: building a better world after COVID-19. Commentary 27 April, 2020. Grantham Research Institute. Retrieved from http://www.lse.ac.uk/GranthamInstitute/news/from-rescue-to-recovery-to-transformation-and-growt h-building-a-better-world-after-covid-19/

Bostrom A, O’Connor RE, Böhm G, Hanss D, Bodi O, Ekström F, Halder P, Jeschke S, Mack B, Qu M, Rosentrater L (2012) Causal thinking and support for climate change policies: international survey findings. Glob Environ Change 22(1):210-222

Burstein P (2003) The impact of public opinion on public policy: a review and an agenda. Polit Res Q 56(1):29-40

Carneiro HA, Mylonakis E (2009) Google Trends: a web-based tool for real-time surveillance of disease outbreaks. Clin Infect Dis 49:1557-1564

Dalton RJ (2013) Citizen politics: public opinion and political parties in advanced industrial democracies, 6th edn. Sage and CQ Press, Thousand Oaks 
Drews S, van den Bergh JC (2016) What explains public support for climate policies? A review of empirical and experimental studies. Clim Policy 16(7):855-876

European Commission (2020) Europe's moment: repair and Prepare for the Next Generation. Communication from the Commission to the European Parliament, the European Council, the Council, the European Economic and Social Committee and the Committee of the Regions COM(2020) 456 final. https://eur-lex.europa.eu/legal-content/EN/TXT/PDF/?uri=CELEX:52020DC045 $6 \&$ from $=$ EN. Accessed 30 June 2020

Genoe A, Rousseau R, Rousseau S (2020) Applying Google Trends' search popularity indicator to professional cycling. Submitted to Journal of Sport Economics

Gertler P, Martinez S, Premand P, Rawlings L, Vermeersch C (2016) Impact evaluation in practice. The World Bank

Helm D (2020) The environmental impacts of the coronavirus. Environ Resource Econ 76:21-38. https ://doi.org/10.1007/s10640-020-00426-z

Herrnstadt E, Muehlegger E (2014) Weather, salience of climate change and congressional voting. J Environ Econ Manag 68(3):435-448

Hu D, Lou X, Xu Z, Meng N, Xie Q, Zhang M, Zou Y, Liu J, Sun G, Wang F (2020) More effective strategies are required to strengthen public awareness of COVID-19: evidence from Google Trends. J Glob Health 10(1):011003. https://doi.org/10.7189/jogh.10.011003

Husnayain A, Fuad A, Su ECY (2020) Applications of google search trends for risk communication in infectious disease management: a case study of COVID-19 outbreak in Taiwan. Int J Infect Dis 95:221-223

IEA (2020) Global energy review 2020. Report. https://www.iea.org/reports/global-energy-review-2020/ global-energy-and-co2-emissions-in-2020\#abstract

Jennings V, Bamkole O (2019) The relationship between social cohesion and urban green space: an avenue for health promotion. Int J Environ Res Publ Health 16(3):452

Kwak SJ, Yoo SH, Han SY (2003) Estimating the public's value for urban forest in the Seoul Metropolitan Area of Korea: a contingent valuation study. Urban Stud 40(11):2207-2221

LaRiviere J, Czajkowski M, Hanley N, Aanesen M, Falk-Petersen J, Tinch D (2014) The value of familiarity: effects of knowledge and objective signals on willingness to pay for a public good. J Environ Econ Manag 68(2):376-389

Le Quéré C, Jackson RB, Jones MW, Smith AJ, Abernethy S, Andrew RM, De-Gol AJ, Willis DR, Shan Y, Canadell JG, Friedlingstein P (2020) Temporary reduction in daily global CO2 emissions during the COVID-19 forced confinement. Nat Clim Change. https://doi.org/10.1038/s41558-020-0797-X

Lin BB, Fuller RA, Bush R, Gaston KJ, Shanahan DF (2014) Opportunity or orientation? Who uses urban parks and why. PLoS one $9(1)$

Lo AY, Jim CY (2010) Willingness of residents to pay and motives for conservation of urban green spaces in the compact city of Hong Kong. Urban For Urban Green 9(2):113-120

Mccallum ML, Bury GW (2013) Google search patterns suggest declining interest in the environment. Biodivers Conserv 22(6-7):1355-1367

Millner A, Ollivier H (2016) Beliefs, politics, and environmental policy. Rev Environ Econ Policy 10(2):226-244

Nature (2020) Embed nature in strategies to reboot economies. Nature 581:119. https://doi.org/10.1038/ d41586-020-01390-w

Nghiem LTP, Papworth SK, Lim FKS, Carrasco LR (2016) Analysis of the capacity of Google Trends to measure interest in conservation topics and the role of online news. PLoS ONE 11(3):e0152802. https://doi.org/10.1371/journal.pone.0152802

Nisbet EK, Zelenski JM, Grandpierre Z (2019) Mindfulness in nature enhances connectedness and mood. Ecopsychology 11(2):81-91

Samuelsson K, Barthel S, Colding J, Macassa G, Giusti M (2020) Urban nature as a source of resilience during social distancing amidst the coronavirus pandemic. Landsc Urban Plan. https://doi. org/10.31219/osf.io/3wx5a

Schultz PW (2002). Inclusion with nature: the psychology of human-nature relations. In: Psychology of sustainable development. Springer, Boston, MA, pp 61-78

Siliverstovs B, Wochner DS (2018) Google Trends and reality: Do the proportions match? Appraising the international informational value of online search behavior: Evidence from Swiss tourism regions. J Econ Behav Organ 145:1-23

Statcounter (2020) https://gs.statcounter.com/search-engine-market-share/all/europe\#monthly-20190 1-202004-bar. Accessed 29 May 2020

Tyrväinen L, Väänänen H (1998) The economic value of urban forest amenities: an application of the contingent valuation method. Landsc Urban Plan 43(1-3):105-118 
UN (2020) First Person: COVID-19 is not a silver lining for the climate, says UN Environment chief. https:// news.un.org/en/story/2020/04/1061082. Accessed 30 June 2020

Wang P, Chen K, Zhu S, Wang P, Zhang H (2020) Severe air pollution events not avoided by reduced anthropogenic activities during COVID-19 outbreak. Resour Conserv Recycl 158:104814. https://doi. org/10.1016/j.resconrec.2020.104814

Whitburn J, Linklater WL, Milfont TL (2019) Exposure to urban nature and tree planting are related to proenvironmental behavior via connection to nature, the use of nature for psychological restoration, and environmental attitudes. Environ Behav 51(7):787-810

Yunus AP, Masago Y, Hijioka Y (2020) COVID-19 and surface water quality: improved lake water quality during the lockdown. Sci Total Environ 731:139012. https://doi.org/10.1016/j.scitotenv.2020.139012

Publisher's Note Springer Nature remains neutral with regard to jurisdictional claims in published maps and institutional affiliations. 